\title{
RESPIRAÇÃO E PRODUÇÃO DE ETANOL E DE ETILENO EM MANGAS ARMAZENADAS SOB DIFERENTES CONCENTRAÇÕES DE DIÓXIDO DE CARBONO E OXIGÊNIO'
}

\author{
RENAR JOÃO BENDER² e JEFFREY BRECHT ${ }^{3}$
}

\begin{abstract}
RESUMO - O objetivo deste trabalho foi avaliar a respiração e produção de etanol e etileno em mangas armazenadas sob reduzidas concentrações de oxigênio $\left(\mathrm{O}_{2}\right)$ e elevadas concentrações de dióxido de carbono $\left(\mathrm{CO}_{2}\right)$. Mangas pré-climatéricas das cultivares Kent e Tommy Atkins foram armazenadas, sob fluxo contínuo, por 14 ou 21 dias, a $12^{\circ} \mathrm{C}$ em três concentrações de $\mathrm{O}_{2}: 3 \%, 5 \%$ ou $21 \%$ em mistura com concentrações de $5 \%, 15 \%, 25 \%, 35 \%, 45 \%, 50 \%$ ou $70 \%$ de $\mathrm{CO}_{2}$. O tratamento-testemunha constou de armazenagem em ar sob fluxo contínuo. Após o período em atmosfera controlada (AC), as mangas foram transferidas e mantidas por 5 dias em ar a $20^{\circ} \mathrm{C}$. Mangas sob concentrações de $50 \%$ e $70 \%$ de $\mathrm{CO}_{2}$ produziram mais etanol que nas demais concentrações de $\mathrm{CO}_{2}$. A redução para $3 \%$ de $\mathrm{O}_{2}$ na atmosfera de armazenagem aparentemente não teve efeito adicional ao $\mathrm{CO}_{2}$ na produção de etanol. A atividade respiratória de mangas em $\mathrm{AC}$ com $\mathrm{CO}_{2}$ acima de $45 \%$ foi muito mais intensa do que a respiração sob as concentrações de $\mathrm{CO}_{2}$ mais baixas; a produção de etileno, no entanto, esteve suprimida, e, mesmo após a transferência para ar, não se recuperou, permanecendo inferior aos demais tratamentos. A queda na atividade respiratória das mangas armazenadas a $50 \%$ e $70 \% \mathrm{de}_{2}$, quando foram transferidas para ar a $20^{\circ} \mathrm{C}$ indica que as elevadas concentrações de $\mathrm{CO}_{2}$ causaram dano irreparável aos tecidos
\end{abstract}

Termos para indexação: Mangifera indica, cultivar Kent, cultivar Tommy Atkins, armazenagem em atmosfera controlada, anaerobiose.

\section{RESPIRATION RATES AND ETHANOL AND ETHYLENE PRODUCTION OF MANGOES STORED UNDER ELEVATED CARBON DIOXIDE AND REDUCED OXIGEN ATMOSPHERES}

\begin{abstract}
The objective of this work was to evaluate respiration rates and ethanol and ethylene production of mangoes stored in controlled atmosphere (CA) with reduced $\mathrm{O}_{2}$ and elevated $\mathrm{CO}_{2}$ concentrations. Pre-climacteric 'Kent' and 'Tommy Atkins' mangoes were stored for 14 or 21 days at $12^{\circ} \mathrm{C}$ in $5 \%, 15 \%, 25 \%, 35 \%, 45 \%, 50 \%$ or $70 \% \mathrm{CO}_{2}$ plus either $21 \%, 5 \%$ or $3 \% \mathrm{O}$ in a flow through CA system at $12{ }^{\circ} \mathrm{C}$. In the control treatment fruits were stored in air at the same temperature and also in the flow through system. After the CA storage the mangoes were transferred and kept for 5 days in air at $20^{\circ} \mathrm{C}$. Mangoes stored in either $50 \%$ or $70 \% \mathrm{CO}_{2}$ had the highest ethanol production rates. The reduction to $3 \%$ of the $\mathrm{O}_{2}$ concentration in the storage atmosphere does not seem to have an additional effect on ethanol production. Respiratory rates of mangoes in CA above $45 \% \mathrm{CO}_{2}$ atmospheres were higher than in the other treatments, while ethylene production rates were the lowest values. After transfer to air at $20^{\circ} \mathrm{C}$, respiration rates of mangoes from these treatments dropped significantly below control levels, which, associated with lower rates of ethylene production, indicate that the mangoes had been damaged by the elevated $\mathrm{CO}_{2}$ atmospheres.
\end{abstract}

Index terms: Mangifera indica, Kent cultivar, Tommy Atkins cultivar, controlled atmosphere storage, anaerobiosis.

\footnotetext{
${ }^{1}$ Aceito para publicação em 28 de junho de 1999.

${ }^{2}$ Eng. Agrôn., Dr., Prof. Adjunto, Dep. de Horticultura e Silvicultura, UFRGS, CEP 91510-970 Porto Alegre, RS. E-mail: rjbe@vortex.ufrgs.br

${ }^{3}$ Eng. Agrôn., Ph.D., Horticultural Sciences Department, University of Florida, Gainesville 32611-0690, FL, EUA
}

\section{INTRODUÇ̃̃o}

O consumo de mangas em países mais desenvolvidos apresentou nas últimas décadas um significativo aumento. Haines (1991) relata um incremento anual de $10 \%$ no volume de mangas importadas pe- 
los Estados Unidos. O transporte marítimo tem sido o meio principal para movimentar os crescentes volumes de fruta no mercado internacional (Medlicott et al., 1990), mas apresenta a desvantagem do tempo que o navio leva para chegar aos portos de desembarque (Noomhorn \& Tiasuwan, 1995). Partindo da América do Sul, Caribe ou México, o navio leva de duas a três semanas para aportar nos Estados Unidos ou na Europa. O tempo de transporte tem influenciado negativamente a qualidade das mangas no mercado internacional em decorrência, principalmente, da colheita no estágio "de vez", prática utilizada para obter uma melhor resistência da polpa e assim diminuir danos de impacto e de pressão em pós-colheita.

Outra prática, que também resulta em perdas qualitativas, é o tratamento com água quente, obrigatório para desinfestação de mosca-das-frutas (Anastrepha suspensa), para o que foram testados tratamentos alternativos, entre os quais, o uso de elevadas concentrações de $\mathrm{CO}_{2}$ ou reduzidas concentrações de $\mathrm{O}_{2}$. Yahia et al. (1989) observaram que uma exposição de cinco dias, a $50 \%$ de $\mathrm{CO}_{2}$ e a uma temperatura de $20^{\circ} \mathrm{C}$, não causou lesões em mangas da cultivar Keitt. Não há informações sobre alterações no metabolismo de mangas submetidas a atmosferas extremas.

Neste trabalho, objetivou-se avaliar a atividade respiratória e a produção de etanol e etileno em mangas armazenadas em atmosfera controlada com altas concentrações de $\mathrm{CO}_{2}$ e reduzidas concentrações de $\mathrm{O}_{2}$.

\section{MATERIAL E MÉTODOS}

Foram conduzidos dois experimentos. No primeiro, mangas das cultivares Tommy Atkins e Kent, recém colhidas em pomares de Homestead e Pine Island/Fort Myers, na Flórida, foram transportadas de carro para as instalações do Departamento de Horticultura/IFAS, Universidade da Flórida, em Gainesville. A colheita baseou-se na cor de fundo da epiderme e no formato e tamanho dos frutos. As mangas foram colocadas, ainda no dia da colheita, em frascos de vidro de 1,75 L de capacidade e mantidos em um sistema de fluxo contínuo em diferentes combinações de $\mathrm{O}_{2}$ e $\mathrm{CO}_{2}$. Os gases para as misturas provinham de cilindros contendo $\mathrm{CO}_{2}, \mathrm{O}_{2}$ e nitrogênio $\left(\mathrm{N}_{2}\right)$ comprimidos Foram aplicados os seguintes tratamentos: $5 \%, 25 \%, 50 \%$ e $70 \%$ de $\mathrm{CO}_{2}$ em mistura com $3 \%$ ou $21 \%$ de $\mathrm{O}_{2}$, por 14 dias na cultivar Tommy Atkins e 21 dias na cultivar Kent. O tratamento-controle foi mantido em ar no sistema de fluxo contínuo. A temperatura de armazenagem foi de $12^{\circ} \mathrm{C}$

O segundo experimento foi conduzido com a cultivar Tommy Atkins importada do México pela importadora Brooks Tropicals de Homestead, Flórida. As mangas foram armazenadas por 21 dias, a $12^{\circ} \mathrm{C}$, em atmosferas de $15 \%, 25 \%, 35 \%$ e $45 \%$ de $\mathrm{CO}_{2}$, misturados a $5 \%$ de $\mathrm{O}_{2}$ Neste experimento, as concentrações de $\mathrm{O}_{2}$ foram obtidas misturando $\mathrm{CO}_{2}$ e $\mathrm{N}_{2}$ a ar fornecido por compressor. $\mathrm{O}$ tratamento-controle foi ar em sistema de fluxo contínuo a $12^{\circ} \mathrm{C}$

Ao final dos 14 ou 21 dias de armazenagem em atmosfera controlada $(\mathrm{AC})$ ou ar a $12^{\circ} \mathrm{C}$, as mangas foram transferidas para uma câmara de amadurecimento e mantidas em ar a $20^{\circ} \mathrm{C}$.

Durante a armazenagem, foram tomadas amostras de ar dos frascos de cada uma das quatro repetições, e injetadas em cromatógrafo a gás (CG), para análises de etanol e etileno. Para determinação da atividade respiratória (produção de $\mathrm{CO}_{2}$ ), a entrada e a saída das misturas de atmosfera nos frascos de vidro foram seladas por duas horas. A primeira amostra da composição da mistura do frasco de vidro foi feita logo após o fechamento das conexões, e a outra amostra foi feita após duas horas, para calcular a atividade respiratória conforme descrito em Talasila et al. (1992).

A produção de etanol foi determinada em um CG Hewlett-Packard, modelo 5890, equipado com uma coluna 80/120 mesh Carbopack B (5\% Carbowax 20M) em níquel de 1520 × 3,12 mm e detector de ionização de chama. O CG foi operado com temperatura na coluna de $140^{\circ} \mathrm{C}$ e detector e injetor a $200^{\circ} \mathrm{C}$. A produção de etileno foi determinada em CG de fotoionização, Photovac 10A10, equipado com uma coluna com alumina ativada 60/80 mesh e de $760 \times 3,18 \mathrm{~mm}$ e operado a temperatura ambiente.

Os experimentos foram conduzidos em delineamento completamente casualizado

\section{RESULTADOS E DISCUSSÃo}

As mangas armazenadas em $50 \%$ ou $70 \%$ de $\mathrm{CO}_{2}$ (Fig. 1) produziram mais etanol que as mangas dos demais tratamentos. Lakshminarayana \& Subrahmanyam (1970) relataram incrementos similares na produção de etanol em mangas da cultivar Alphonso, armazenadas a temperaturas em torno de $12^{\circ} \mathrm{C}$, por 21 dias, em concentração elevada de $\mathrm{CO}_{2}$ 
em comparação a mangas armazenadas em ar. O’Hare \& Prasad (1993) obtiveram resultados semelhantes
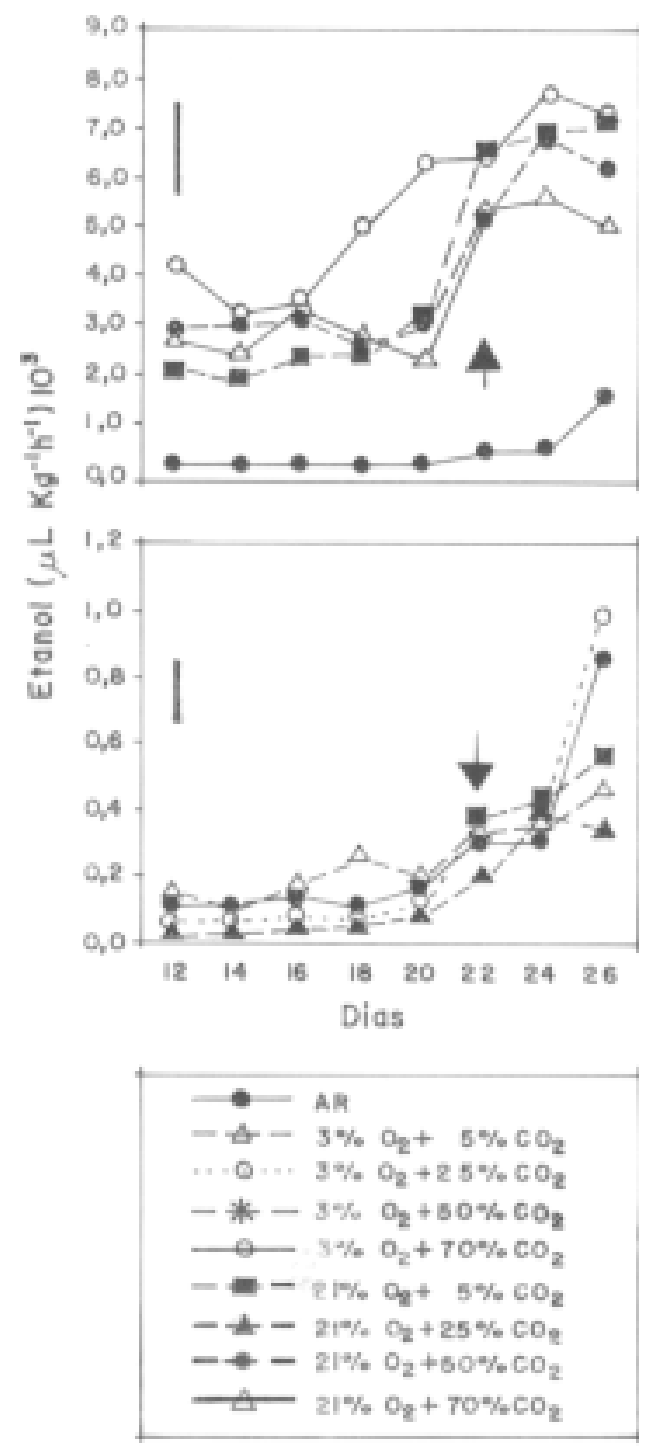

FIG. 1. Produção de etanol de mangas cultivar Kent armazenadas durante 21 dias em atmosfera controlada com diferentes concentrações de $\mathrm{CO}_{2}$ e $\mathrm{O}_{2}$ a $12^{\circ} \mathrm{C}$ e durante 5 dias em ar a $20^{\circ} \mathrm{C}$. A seta indica a transferência para ar a $20^{\circ} \mathrm{C}$. $O$ tratamento controle consistiu do armazenamento das mangas em ar refrigerado a $12^{\circ} \mathrm{C}$. (Barra vertical $=$ diferença mínima significativa a $\mathbf{p}<\mathbf{0 , 0 5}$ ). em mangas da cultivar Kensington, em atmosfera com concentrações de $\mathrm{CO}_{2}$ acima de $10 \%$ por até cinco semanas, a $7^{\circ} \mathrm{C}$. Além disso, observaram que as mangas eram facilmente identificáveis pelo aroma e pela descoloração na epiderme. No presente trabalho, foram observadas alterações na coloração da epiderme das mangas apenas nos tratamentos com concentração de $\mathrm{CO}_{2}$ igual ou superior a $45 \%$.

As concentrações de $\mathrm{O}_{2}$ não influenciaram significativamente a produção de etanol, o que pode ser uma indicação de que altas concentrações de $\mathrm{CO}_{2}$ mascaram o efeito de baixas concentrações de $\mathrm{O}_{2}$, considerando que isto já foi observado em abacates (Kanellis et al., 1989) e pêras (Ke et al., 1994), nas quais, concentrações de $\mathrm{O}_{2}$ abaixo de $5 \%$ induziram isoenzimas da álcool-deidrogenase $(\mathrm{ADH})$ resultando em maior produção de etanol.

A atividade respiratória de mangas da cultivar Kent nos tratamentos de $50 \%$ e $70 \%$ de $\mathrm{CO}_{2}$ foi significativamente mais intensa durante a armazenagem em $\mathrm{AC}$ do que a do controle, enquanto que a respiração das mangas dos tratamentos com $5 \%$ e $25 \%$ de $\mathrm{CO}_{2}$ não diferiu do controle (Fig. 2). Após transferir para ar a $20^{\circ} \mathrm{C}$, a atividade respiratória das mangas do controle e dos tratamentos com $5 \%$ e $25 \%$ de $\mathrm{CO}_{2}$ duplicou, ao passo que a atividade respiratória das mangas dos tratamentos com $50 \%$ e $70 \%$ de $\mathrm{CO}_{2}$ diminuiu significativamente, o que deve ser uma indicação de que houve dano irreparável aos tecidos. Neste experimento também não houve diferenças na produção de $\mathrm{CO}_{2}$ que pudessem ser associadas à concentração de $\mathrm{O}_{2}$

Logo após transferir para ar a $20^{\circ} \mathrm{C}$ as mangas da cultivar Tommy Atkins armazenadas por 21 dias em concentrações de $\mathrm{CO}_{2}$ até $45 \%$ não apresentaram diferença na respiração (Fig. 3). Todos os tratamentos com $\mathrm{CO}_{2}$, exceto o tratamento com $45 \%$ de $\mathrm{CO}_{2}$, recuperaram o controle do metabolismo respiratório após cinco dias em ar a $20^{\circ} \mathrm{C}$, uma vez que o padrão de respiração foi semelhante ao do tratamento-testemunha.

A alta atividade respiratória e produção de etanol de mangas armazenadas em atmosferas de $\mathrm{CO}_{2}$ acima de $25 \%$ indicam claramente uma intensa anaerobiose, evidenciada também pela presença de aroma típico de tecido em fermentação. O mecanismo pelo qual altas concentrações de $\mathrm{CO}_{2}$ estimulam 
a respiração anaeróbica provavelmente envolve a inibição de enzimas do ciclo dos ácidos tricarboxílicos, especialmente a succinato-deidrogenase
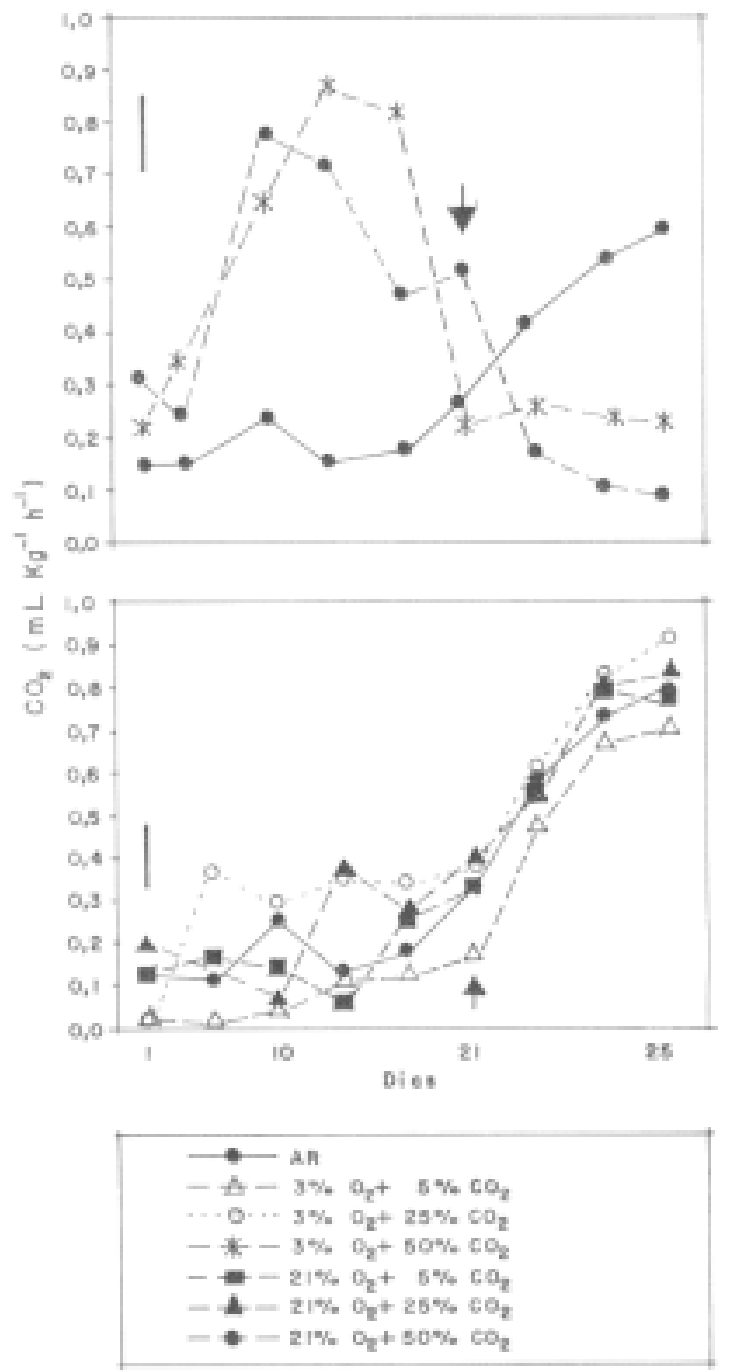

FIG. 2. Atividade respiratória de mangas cultivar Kent armazenadas durante 21 dias em atmosfera controlada com diferentes concentrações de $\mathrm{CO}_{2}$ e $\mathrm{O}_{2}$ a $12^{\circ} \mathrm{C}$ e durante 5 dias em ar a $20^{\circ} \mathrm{C}$. A seta indica transferência para ar a $20^{\circ} \mathrm{C}$. $\mathrm{O}$ tratamento controle consistiu do armazenamento das mangas em ar refrigerado a $12^{\circ} \mathrm{C}$. (Barra vertical $=$ diferença mínima significativa a $\mathbf{p}<0,05$ ).
(Monning, 1983; Kubo et al., 1990). Além do mais, como já foi indicado por Ke et al. (1995), quando o transporte de elétrons e a oxidação fosforilativa estão sendo inibidos, a única fonte de produção de energia para a manutenção dos tecidos é por fosforilação de substrato na via glicolítica, sendo que esta rota depende da disponibilização de potencial de redução via rota fermentativa (Leblova, 1978).

O continuado incremento na produção de etanol, acompanhado pelo decréscimo na atividade respiratória de mangas dos tratamentos com $50 \% \mathrm{e} 70 \% \mathrm{de}$ $\mathrm{CO}_{2}$ após a transferência para ar a $20^{\circ} \mathrm{C}$, pode ser decorrência de dano irreversível na estrutura dos mitocôndrios, em conseqüência da prolongada exposição a extremas concentrações de $\mathrm{CO}_{2}$. Em contrapartida, Moriguchi \& Romani (1995) observaram que mitocôndrios de abacates apresentaram a

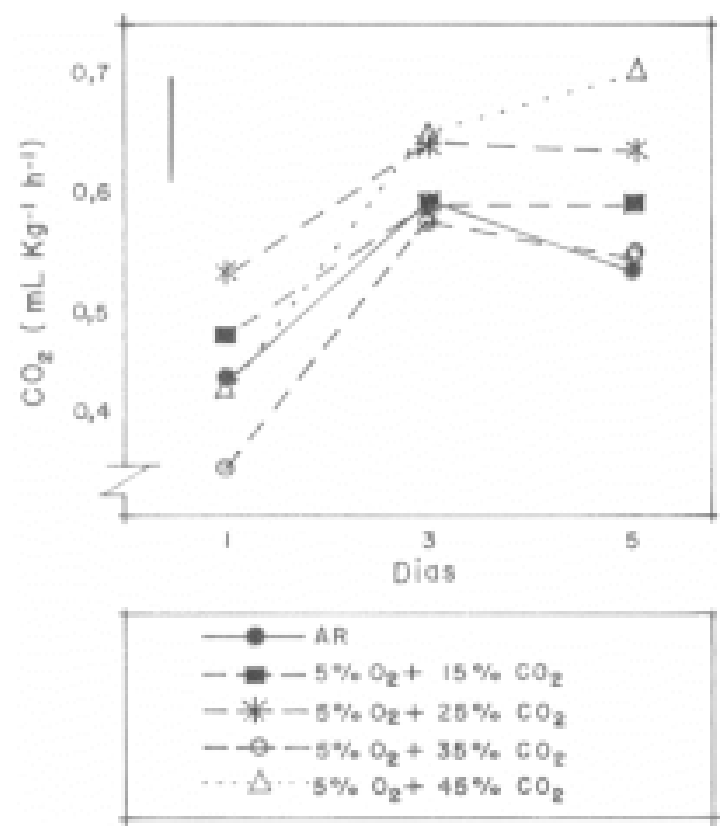

FIG. 3. Atividade respiratória de mangas cultivar Tommy Atkins armazenadas durante 5 dias em ar a $20^{\circ} \mathrm{C}$ após armazenagem por 21 dias em atmosfera controlada com diferentes concentrações de $\mathrm{CO}_{2}$ e $\mathrm{O}_{2}$. O tratamento controle consistiu do armazenamento das mangas em ar refrigerado a $12^{\circ} \mathrm{C}$. (Barra vertical $=$ diferença mínima significativa a $\mathbf{p}<\mathbf{0 , 0 5}$ ). 
habilidade de recuperar o controle respiratório após curta exposição a $75 \% \mathrm{CO}_{2}$.

Mangas expostas a $5 \%$ e a $25 \% \mathrm{CO}_{2}$ por 14 dias, a $12^{\circ} \mathrm{C}$, recuperaram a atividade respiratória após transferência para ar a $20^{\circ} \mathrm{C}$, o que indica que o transporte de elétrons não estava completamente suprimido, e que também não houve danos severos ao sistema (Fig. 4). Ke et al. (1995) observaram que o sistema de transporte de elétrons em abacates submetidos por três dias a $80 \%$ de $\mathrm{CO}_{2}$ e níveis de ambiente de $\mathrm{O}_{2}$ a $20^{\circ} \mathrm{C}$ foi apenas parcialmente inibido.

A produção de etileno de mangas do tratamento controle da cultivar Kent foi superior à de mangas mantidas em atmosfera de $50 \%$ e $70 \%$ de $\mathrm{CO}_{2}$ durante o período de amadurecimento por cinco dias em ar
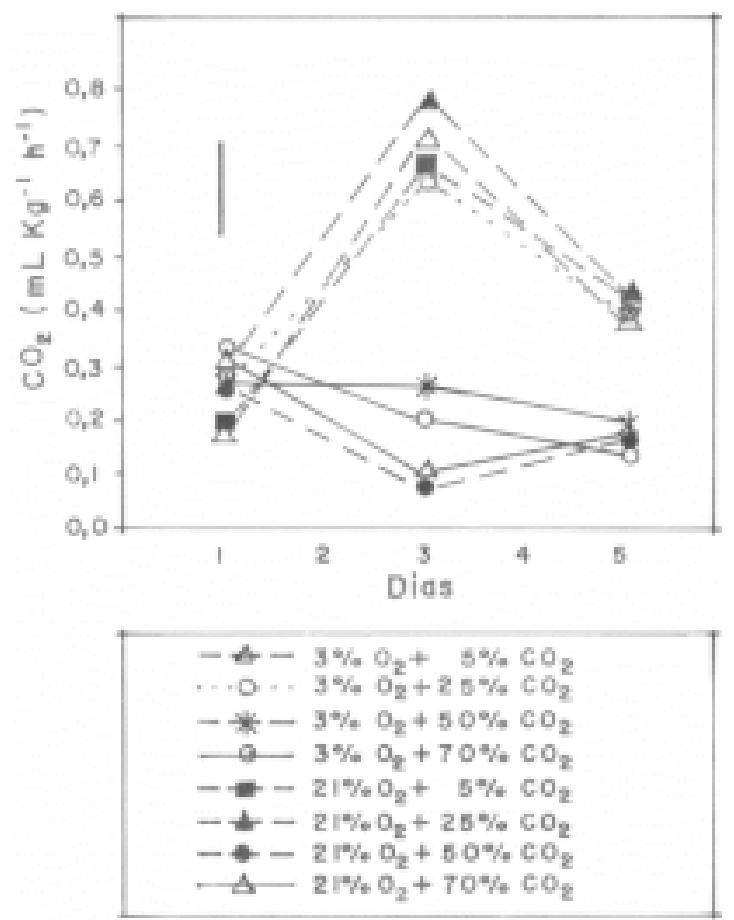

FIG. 4. Atividade respiratória de mangas cultivar Tommy Atkins armazenadas durante 5 dias em ar a $20^{\circ} \mathrm{C}$ após armazenagem por 14 dias em atmosfera controlada com diferentes concentrações de $\mathrm{CO}_{2}$ e $\mathrm{O}_{2}$ a $12^{\circ} \mathrm{C}$. O tratamento controle consistiu do armazenamento das mangas em ar refrigerado a $12^{\circ} \mathrm{C}$. (Barra vertical $=$ diferença mínima significativa a $\mathbf{p}<\mathbf{0 , 0 5}$ ). a $20{ }^{\circ} \mathrm{C}$ (Fig. 5). Mesmo que as atmosferas de $50 \%$ e $70 \%$ de $\mathrm{CO}_{2}$ tenham estimulado a respiração anaeróbica, a produção de etileno não aumentou como seria de se esperar numa condição de estresse. Este fato pode indicar que a produção de etileno foi inibida pelas altas concentrações de $\mathrm{CO}_{2}$, como já foi demonstrado em outras espécies (Cheverry et al., 1988; Kerbel et al., 1988; Rothan \& Nicolas, 1994).

A produção significativamente menor de etileno nas mangas da cultivar Kent (Fig. 5) sob atmosfera de $50 \%$ e $70 \%$ de $\mathrm{CO}_{2}$ pode ser conseqüência do efeito inibidor do $\mathrm{CO}_{2}$ sobre a ácido-carboxílico-1aminociclopropano (ACC) oxidase, conforme conclusões de Rothan \& Nicolas (1994). Mesmo que tenha sido comprovado por Dong et al. (1992), em maçãs, que o $\mathrm{CO}_{2}$ é um ativador essencial da $\mathrm{ACC}$ oxidase e, portanto, pode conduzir a uma maior pro-
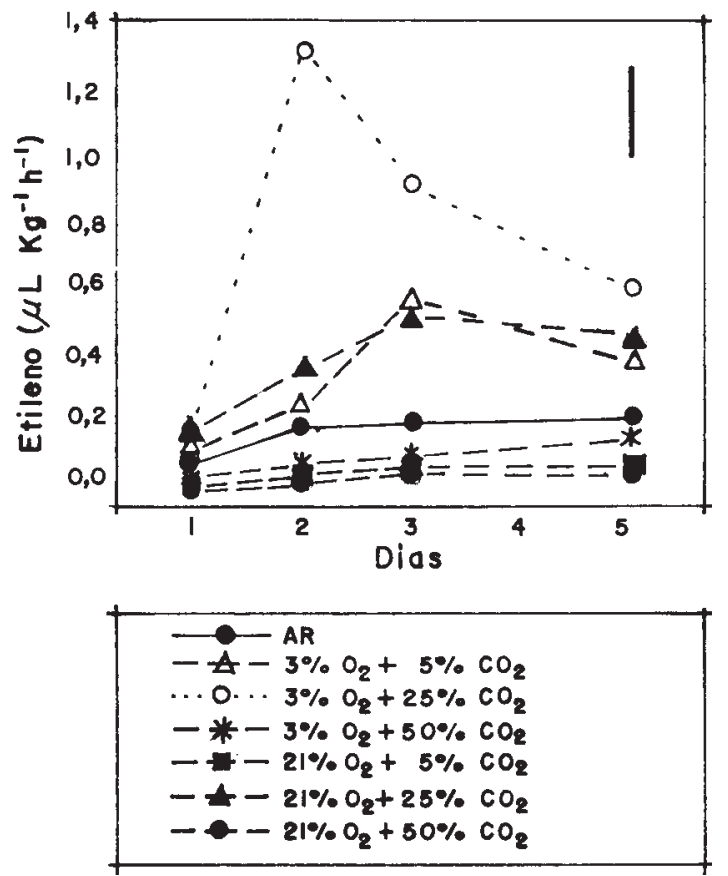

FIG. 5. Produção de etileno de mangas cultivar Kent armazenadas durante 5 dias em ar a $20^{\circ} \mathrm{C}$ após armazenagem por 21 dias em atmosfera controlada com diferentes concentrações de $\mathrm{CO}_{2}$ e $\mathrm{O}_{2}$ a $12^{\circ} \mathrm{C}$. $\mathrm{O}$ tratamento controle consistiu do armazenamento das mangas em ar refrigerado a $12^{\circ} \mathrm{C}$. (Barra vertical $=$ diferença mínima significativa a $\mathbf{p}<\mathbf{0 , 0 5}$ ).

Pesq. agropec. bras., Brasília, v.35, n.5, p.865-871, maio 2000 
dução de etileno, é provável que a exposição por 14 e 21 dias a concentrações acima de $50 \%$ de $\mathrm{CO}_{2}$ esteja além do nível de estímulo para a atividade da ACC oxidase.

Os níveis de $\mathrm{O}_{2}$ nos experimentos do presente trabalho tiveram pouca influência na biossíntese de etileno das mangas 'Kent' e 'Tommy Atkins' (Figs. 5 e 6). Apesar da necessidade de $\mathrm{O}_{2}$ para a oxidação do ACC para etileno (Yang, 1985), os 3\% de $\mathrm{O}_{2}$ empregados nestes experimentos provavelmente ainda são muito acima do aparente $\mathrm{K} m$ para a ACC oxidase em mangas, utilizando como analogia o $\mathrm{Km}$ de $0,4 \%$ de $\mathrm{O}_{2}$ determinado por Kuai \& Dilley (1992) em maçãs.

A produção de etileno de mangas da cultivar Kent após a transferência para ar a $20^{\circ} \mathrm{C}$ dos tratamentos de $3 \%$ misturados a $5 \%$ ou $25 \%$ de $\mathrm{CO}_{2}$ e níveis ambientais de $\mathrm{O}_{2}$ misturados a $25 \%$ de $\mathrm{CO}_{2}$ apresen-

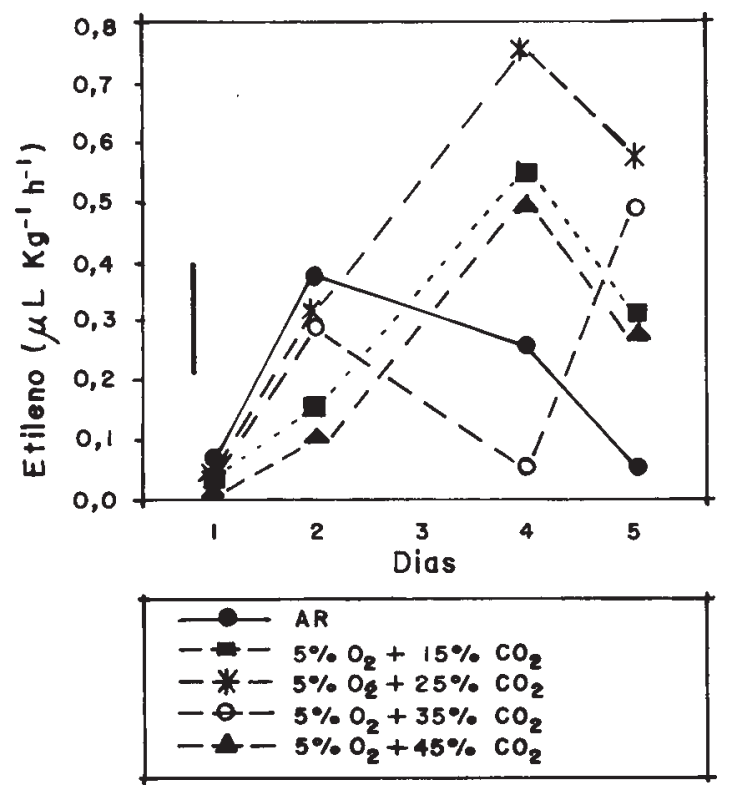

FIG. 6. Produção de etileno de mangas cultivar Tommy Atkins armazenadas durante 5 dias em ar a $20^{\circ} \mathrm{C}$ após armazenagem por 21 dias em atmosfera controlada com diferentes concentrações de $\mathrm{CO}_{2}$ e $\mathrm{O}_{2}$ a $12^{\circ} \mathrm{C}$. O tratamento controle consistiu do armazenamento das mangas em ar refrigerado a $12^{\circ} \mathrm{C}$. (Barra vertical $=$ diferença mínima significativa a $\mathbf{p}<\mathbf{0 , 0 5}$ ). taram produção significativamente superior à dos frutos do tratamento-controle (Fig. 5). Esta maior produção de etileno pode indicar uma resposta ao estresse, mesmo que a atividade respiratória (Fig. 2) não sinalize isto.

Mangas da cultivar Tommy Atkins armazenadas por 21 dias em atmosferas de até $45 \%$ de $\mathrm{CO}_{2}$ voltaram a produzir etileno após transferência para ar a $20^{\circ} \mathrm{C}$ (Fig. 6). A recuperação da produção de etileno neste experimento pode indicar que o metabolismo foi apenas parcialmente inibido sob concentrações de $\mathrm{CO}_{2}$ entre $25 \%$ e $45 \%$. E, sobretudo, pode indicar a possibilidade de ocorrer dano irreparável aos tecidos de mangas se estas forem armazenadas por períodos maiores do que 14 dias em concentrações de $\mathrm{CO}_{2}$ iguais ou superiores a $50 \%$.

\section{CONCLUSÕES}

1. A armazenagem de mangas das cultivares Kent e Tommy Atkins em atmosferas de $\mathrm{CO}_{2}$ superiores a $25 \%$, por 14 ou 21 dias, resulta em incrementos na atividade respiratória e no metabolismo anaeróbico que podem causar prejuízos à qualidade dos frutos.

2. Concomitantemente ao aumento do metabolismo anaeróbico em atmosferas com elevado $\mathrm{CO}_{2}$ ocorre a redução da produção de etileno, e após transferência para ar não ocorre retomada da biossíntese de etileno nos níveis observados em mangas apenas armazenadas em ar.

3. A redução da concentração de $\mathrm{O}_{2}$ da atmosfera ambiente para $3 \%$, na presença de elevado $\mathrm{CO}_{2}$ tem pouco efeito nas produções de etanol e de etileno.

\section{REFERÊNCIAS}

CHEVERRY, J.L.; SY, M.O.; POULIQUEN, J.; MARCELLIN, P. Regulation by $\mathrm{CO}_{2}$ of 1-aminocyclopropane-1-carboxylic acid conversion to ethylene in climacteric fruits. Physiologia Plantarum, Copenhagen, v.72, p.535-540, 1988.

DONG, J.G.; FERNANDEZ-MACULET, J.C.; YANG, S.F. Purification and characterization of 1-aminocyclopropane-1-carboxylate oxidase from apple fruit. National Academy of Science of the United States of America. Proceedings, Washington, v.89, p.9789-9793, 1992 
HAINES, W. The world mango situation: a market perspective. Acta Horticulturae, Wageningen, v.291, p.1-11, 1991.

KANELLIS, A.K.; SOLOMOS, T.; MATTOO, A.K Hydrolytic enzyme activities and protein pattern of avocado fruit ripened in air and low oxygen, with and without ethylene. Plant Physiology, Rockville, v.90, p.259-266, 1989.

KE, D.; YAHIA, E.; HESS, B.; ZHOU, L.; KADER, A.A Regulation of fermentative metabolism in avocado fruit under oxygen and carbon dioxide stresses. American Society for Horticultural Science. Journal, Alexandria, v.120, p.481-490, 1995.

KE, D.; YAHIA, E.; MATEOS, M.; KADER, A.A Ethanolic fermentation of 'Bartlett' pears as influenced by ripening stage and atmospheric composition. American Society for Horticultural Science. Journal, Alexandria, v.119, p.976-982, 1994.

KERBEL, E.L.; KADER, A.A.; ROMANI, R.J. Effects of elevated $\mathrm{CO}_{2}$ concentrations on glycolysis in intact 'Bartlett' pear fruit. Plant Physiology, Rockville, v.86, p. 1205-1209, 1988

KUAI, J.; DILLEY, D.R. Extraction, partial purification and characterization of 1-aminocyclopropane-1carboxylic acid oxidase from apple fruit. Postharvest Biology and Technology, Amsterdam, v.1, p.203211,1992

KUBO, Y.; INABA, A.; NAKAMURA, R. Respiration and $\mathrm{C}_{2} \mathrm{H}_{4}$ production in various harvested crops held in $\mathrm{CO}_{2}$-enriched atmospheres. American Society for Horticultural Science. Journal, Alexandria, v.115, p.975-978, 1990

LAKSHMINARAYANA, S.; SUBRAHMANYAM, H Carbon dioxide injury and fermentative decarboxylation in mango fruit at low temperature storage. Journal of Food Science and Technology, Mysore, v.7, p.148-152, 1970

LEBLOVA, S. Pyruvate conversions in higher plants during natural anaerobiosis. In: HOOK, D.D.; CRAWFORD, R.M.M. (Eds.). Plant life in anaerobic environments. Ann Arbor : Ann Arbor Science, 1978. p.155-168, 1978.

MEDLICOTT, A.P.; SIGRIST, J.M.M.; SY, O. Ripening of mangoes following low-temperature storage. American Society for Horticultural Science. Journal, Alexandria, v.115, p.430-434, 1990

MONNING, A. Studies on the reaction of Krebs cycle enzymes from tissue (cv. Cox's Orange) to increased levels of $\mathrm{CO}_{2}$. Acta Horticulturae, Wageningen, v.138, p.113-119, 1983

MORIGUCHI, T.; ROMANI, R.J. Mitochondrial selfrestoration as an index to the capacity of avocado fruit to sustain atmospheric stress at two climacteric stages. American Society for Horticultural Science. Journal, Alexandria, v.120, p.643-649, 1995.

NOOMHORN, A.; TIASUWAN, N. Controlled atmosphere storage of mango fruit, Mangifera indica L. cv. Rad. Journal of Food Processing and Preservation, Trumbull, v.19, p.271-281, 1995.

O'HARE, T.J.; PRASAD, A. The effect of temperature and carbon dioxide on chilling symptoms in mango. Acta Horticulturae, Wageningen, v.343, p.244-249, 1993

ROTHAN, C.; NICOLAS, J. High $\mathrm{CO}_{2}$ levels reduce ethylene production in kiwifruit. Physiologia Plantarum, Copenhagen,v.92, p.1-8, 1994.

TALASILA, P.C.; CHAU, K.W.; BRECHT, J.K. Effects of gas concentrations and temperature on $\mathrm{O}_{2}$ consumption of strawberries. Transactions of the ASAE, Saint Joseph, v.35, p.221-224, 1992.

YAHIA, E.M.; MEDINA, F.; RIVERA, M. The tolerance of mango and papaya to atmospheres containing very high levels of $\mathrm{CO}_{2}$ and/or very low levels of $\mathrm{O}_{2}$ as a possible insect control treatment. In: INTERNATIONAL CONTROLLED ATMOSPHERE RESEARCH CONFERENCE, 5., 1989, Wenatchee Proceedings. Wenatchee : [s.n.], 1989. v.2, p.77-89

YANG, S.F. Biosynthesis and action of ethylene. HortScience, Alexandria, v.20, p.41-45, 1985. 